\title{
STANDART PELAYANAN MINIMAL (SPM) DAN SISTEM LASING PADA KAPAL RO-RO UNTUK KESELAMATAN TRANSPORTASI PENYEBRANGAN LAUT (Studi Kasus KMP. LEGUNDI)
}

\author{
Zulfaidah Ariany, A Hendra, Samual Febriary \\ Program Studi DIII Teknik Perkapalan Departemen Teknologi Industri \\ Sekolah Vokasi Universitas Diponegoro Semarang \\ Jalan Prof. Sudharto, SH Tembalang Semarang
}

\begin{abstract}
Zulfaidah Ariany, A Hendra, Samual Febriary, in this paper explain that LEGUNDI is a Passanger Ship which has a Surabaya - Lombok shipping route capable of transporting passengers and vehicles in relatively large numbers. Research Minimum Service Standards (SPM) and Lasing System on Ro-Ro Ship for Marine Transportation Safety is aimed to know about Minimum Service Standards (SPM) and how to handle the Lasing system on Ro-Ro KMP LEGUNDY. The reference used is Minister of Transportation Regulation no 30 of 2016 regarding minimum service standard. The analysis used is simulation of shear load calculation on vehicle in Car Deck so get output layout of vehicle parking layout. The result of simulation of the calculation got the total load when the car shifted 35,5 KN then it can be suggested using breaking strength: $60 \mathrm{kN}(6$ ton) and Weight $0.35 \mathrm{~kg}$ based on Break Load Capacity Table for Chain Lasingbe typed in one paragraph and onecolumn format.
\end{abstract}

Keywords: Minimum Service Standards (SPM); Lasing System; Ferry RO-Ro Ship

\section{PENDAHULUAN}

Negara Indonesia merupakan negara kepulauan yang terletak diantara samudera Pasifik dan Samudera Hindia. Sehingga transportasi laut menjadi sangat diperlukan dalam prose distribusi ke tiap-tiap daerah. Luas lutannya mencapai 75 persen dari luas wilayahnya. Contoh studi kasus kapal yang mengalami kecelakaan yaitu KM Senopati Nusantara dioperasikan oleh perusahaan pelayaran PT. Prisma Vista ,Kapal berjenis Ro-Ro berbobot 2.718 GT dan memiliki kapasitas penumpang 1250 orang. Dugaan awal menghilangnya kapal dikarenakan cuaca yang buruk dan lepasnya pengikat kendaraan khussunya truk-truk besar sehingga kendaraan terhempas oleng melebihi batas maksimum sehingga mengakibatkan kapal terbalik $^{[1]}$.

Selain itu dimensi kapal pada lintasan penyeberangan harus diperhatikan, termasuk tinggi sarat, tinggi kapal, dan tinggi freeboat karena dapat mempengaruhi keadaan ketika berlayar dan bersandar.

Proses pemeriksaan SPM dilakukan agar ketika kapal beroperasi tidak menimbulkan masalah (kecelakaan) karena SPM yang di tentukan oleh Pihak Kementrian Perhubungan adalah finishing dari standarisasi klas dan syahbandar, SPM yang di tentukan oleh Kementerian disusun berdasarkan Safety of live at sea (SOLAS).

Proses pengikatan kendaraan pada kapal bertujuan untuk menjaga muatan kapal agar tidan bergerak dan tetap pada tempatnya. Semua pelayaran harus memenuhi standar lashing yang telah di tentukan, jika tidak kapal seharusnya tidak di beri izin Surat Persetujuan Berlayar (SPB)

\section{Kapal Ro-Ro ( Roll On - Roll Over)}

Kapal ini memiliki rampdoor untuk keluar masuknya kendaraan dari kapal keplabuhan maupun dari pelauhan ke kapal. Kapal penyebrangan antar pulau dalam operasinya mengankut penumpang berserta kendaraannya. Umumnya kendaraan yang diangkut adalah kendaraan milik pribadi penumpang, bus angkutan kota, truk-truk pengankut barang dan lainlainya.Kapal jenis ini berfungsi sebagai penghubung antar pulau di indonesia . untuk keluar masukna pada kapal ini terdapat pintu ramdoor yang dapat dibuka saat bersandar di pelabuhan ${ }^{[2]}$.

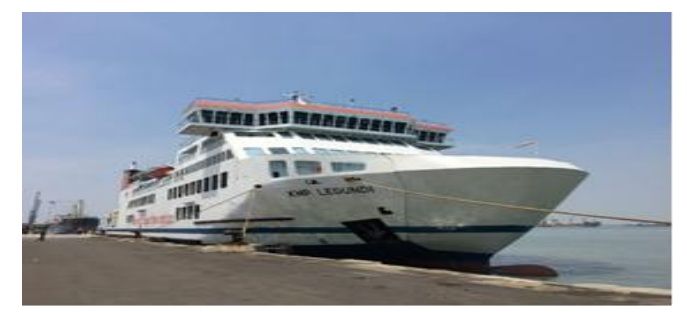

Gambar 1. Kapal Ro-Ro Legundi

\section{Standart Pelayanan Minimal}

Merupakan suatu standart yang wajib dilakukan pada kapal yang akan masuk lintas penyebrangan. Hal ini berlaku untuk kapal -kapal baru ataupun yang baru selesai melaksanakan docking tahunan. Pemeriksaan SPM dilakukan bersama-sama dengan Tim Teknis dari Direktorat Jenderal Perhubungan Darat. Pemeriksaan meliputi aspek pelayanan penumpang sebagaimana telah diatur di dalam Peraturan Menteri Perhubungan 
maupun Keputusan Direktur Jenderal Perhubungan $\operatorname{Darat}^{[3]}$

\section{Gerakan Dan Gaya Pada Kapal}

Fenomena yang terjadi di laut kapal yang berlayar menghadapi gelombang-gelombang dengan periode gelombang yang panjang mengalami situasi yang berbahaya. Dalam memperoleh perlakuan dari gelombang kapal mengalami 2 jenis gerakan yaitu:

- Gerakan rotasi, gerak ini merupakan gerakputaran meliputi: rolling, pitching dan yawing.

- Gerakan translasi (linear), gerak ini merupakan gerak lurus beraturan sesuai dengan sumbunya meliputi: surging, swaying dan heaving

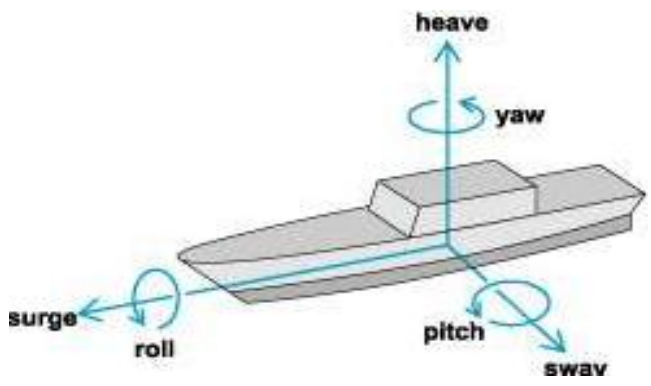

Gambar 2. Simulasi gerakan pada kapal

Diantara gerakan tersebut dapat menyebabkan muatan atau kendaraan didalam kapal bergeser pada bidang miring, sehingga berakibat kepada stabilitas kapal ${ }^{[4]}$

\section{Teori Gaya}

Ketika bendda dalam keadaan miring maka terlibat beberapa gaya yang mempengaruhinya misal perubahan arah gerak, bentuk dan kecepatan.

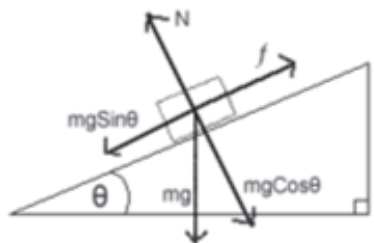

Gambar 3.Gaya pada bidang miring

Gaya gesek adalah gaya yang bekerja pada benda dan arahnya selalu melawan arah gerak benda. Gaya gesek hanya akan bekerja pada benda jika ada gaya luar yang bekerja pada benda tersebut. Gaya dapat berupa zat padat dengan zat padat dan zat cair dengan zat padat ${ }^{[5]}$.

Perbandingan General Requirements of Cargo Securing untuk Beberapa Transportasi.

- $\quad$ Sliding
Untuk cargo sebesar $1000 \mathrm{~kg}$ dengan gaya gesek dengan lantai 0.3 untukbeberapa mode transportasi.

- $\quad$ Tipping

Untuk cargo sebesar $1000 \mathrm{~kg}$ dengan posisi seperti gambar di bawah ini dan rasio tinggi/lebar sama dengan 3.

\section{Metode Pemarkiran Mobil}

Kapal ferry mengangkut berbagai jenis kendaraan yang bertujuan untuk menyeberang ke pulau sesuai dengan rute kapal yang sudah ditentukan. Dengan demikian banyaknya kendaraan yang masuk dalam kapal, maka sudah seharusnya diperlukan pengaturan penempatan kendaraan tersebut $^{[6]}$. Namun mengatur penempatannya saja tidaklah cukup untuk memberikan keamanan di dalam kapal. Oleh karena itu dibuatlah usaha-usaha untuk menghindari berubahnya posisi kendaraan yang sudah ditempatkan pada posisi bilamana tidak akan mengganggu kestabilan kapal. Cara-cara yang dipakai diantaranya yaitu :

- Penggunaan tiang penyangga.

Penggunaan tiang penyangga ini umumnya tidak tersedia pada kapal ferry yang digunakan untuk penyeberangan penumpang, namun tersedia pada kapalkapal pengangkut mobil (car carrier) yang mendistribusikan mobil ke konsumen.Penggunaan tiang penyangga ini ditujukan untuk menjaga posisi mobil yang dibawa oleh kapal agar tidak menggangu stabilitas $^{[7]}$.

- Penggunaan Pengikat.

Pada kapal ferry saat ini mobil yang berupa truk besar diberi ikatan menggunakan pengikat untuk mencegah bergesernya truk tersebut ${ }^{[7]}$.

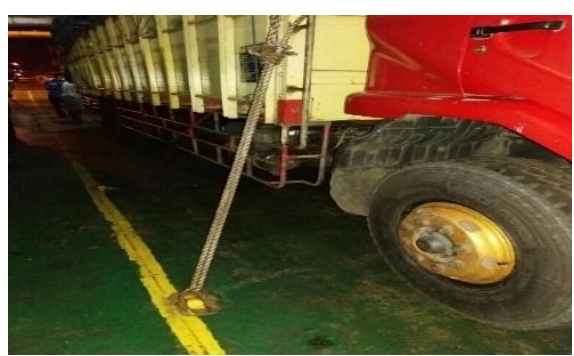

Gambar 4. Pengikat pada kendaraan

- Penggunaan balok

Biasanya penggunaan balok untuk mengganjal roda kendaraan agar tidak menggelinding. Bila yang punya kendaraan lupa memakai rem tangan atau kendaraan tersebut rusak rem tangannya, maka balok ini sangatlah membantu.
Hasil Dan Pembahasan
Ukuran Utama Kapal
Nama kapal
: KMP. LEGUNDI
GT / NT
: 5556 GT / 2205 NT
IMO Number/MMSI 
Tipe kapal

: Ferry RORO Twin

Screws

Galangan pembangun : PT. Dumas Tanjung

Perak Shipyard, Surabaya

Tempat, tahun pembangunan: Surabaya, 2012

Bendera / Call Sign Indonesia / YHRR

Klass : BKI

Pelabuhan Pendaftaran: Surabaya

Kapasitas Penumpang : 812 penumpang

Kapasitas kendaraan : 77 sedan, 37 truk sedang, 2 tronton, 26 trailer

Rescue Boat

:2 unit @ 50 persons

Life Jacket

: 1080 set (dewasa 980

set, anak-anak 100 set)

Tanda Selar

: GT 5556 No 2980 Ka

Ukuran Utama:

Panjang keseluruhan $\quad: 109.40 \mathrm{M}$

Panjang geladak utama $\quad$ : $96.00 \mathrm{M}$ (Car Deck 01)

Panjang garis air $\quad: 100.20 \mathrm{M}$

Panjang antara garis tegak : $99.20 \mathrm{M}$

Lebar maksimal $\quad: 19.60 \mathrm{M}$

Tinggi geladak $\quad: 5.60 \mathrm{M}$

Tinggi sarat $\quad: 4.10 \mathrm{M}$

Kapasitas tanki bahan bakar: 279 ton

Kapasitas tanki air tawar : 400 ton (tank 01

SB/PS, tank 02 SB/PS, center)

Kapasitas tanki ballast : 844 ton

Bow Thruster $\quad: 1$ x 600 KW yang

dituliskan

Pengawasan Kewajiban Pengikatan Kendaraan Pada Kapal Angkutan Penyeberangan

Sesuai Peraturan Menteri Perhubungan Nomor 30 tahun 2016 tentang Kewajiban Pengikatan Kendaraan Pada Kapal Angkutan Penyeberangan, maka Kantor Otoritas Pelabuhan Penyeberangan berfungsi untuk melakukan pengawasan pelaksanaannya.

Sesuai ketentuan dalam peraturan ini ditetapkan bahwa:

- Kendaraan yang wajib diikat (lashing) adalah yang ditempatkan di bagian haluan, bagian tengah (midship), dan bagian buritan geladak kendaraan;

- Kendaraan yang berada di antaranya tidak wajib dilashing namun hanya dilakukan klem roda;

- Jarak maksimal antar kendaraan depan belakang adalah $30 \mathrm{~cm}$ dan kiri kanan adalah $60 \mathrm{~cm}$

Selain itu berdasarkan studi pengamatan di lapangan, pelaksanaan pengikatan kendaraan dan pengaturan jarak antar kendaraan sesuai peraturan tersebut belum dilaksanakan secara maksimal. Beberapa permasalahan yang teridentifikasi di lapangan dapat dijelaskan antara lain:

- Belum adanya kesadaran perusahaan pelayaran untuk menerapkan pengikatan kendaraan sesuai ketentuan;
- Pengawasan pelaksanaan oleh petugas OPP yang cenderung masih lemah;

- Belum ada standar perlengkapan pengikat kendaraan (lashing) dan metode lashing sehingga ditemukan berbagai variasi tali lashing maupun cara pengikatan kendaraan pada kapal;

- Belum ada standar perlengkapan klem roda kendaraan yang tidak wajib lashing;

- Perusahaan pelayaran cenderung untuk memaksimalkan ruang muat kendaraan hingga tidak mempertimbangkan jarak maksimal antar kendaraan sesuai ketentuan dalam peraturan ini.

- Pengawasan yang kurang ketat oleh petugas OPP kemungkinan karena kurangnya pengetahuan akan dampak yang ditimbulkan jika kendaraan tidak dilashing pada kapal.

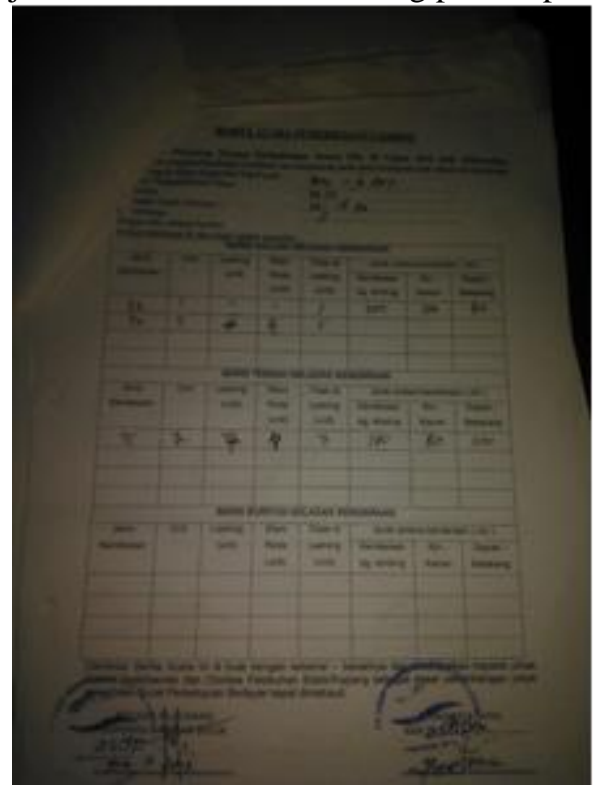

Gambar 5.Berita Acara pengaturan Lasing

\section{Pemeriksaan Standar Pelayanan Minimal}

Pemeriksaan meliputi aspek pelayanan penumpang sebagaimana telah diatur di dalam Peraturan Menteri Perhubungan maupun Keputusan Direktur Jenderal Perhubungan Darat.

Dari hasil keikutsertaan dalam pemeriksaan, hampir semua kapal yang diperiksa telah memenuhi persyaratan SPM kecuali ada catatan-catatan kecil yang tidak terlalu signifikan. Dalam kondisi seperti ini, maka perusahaan pelayaran akan diberikan waktu untuk memperbaiki atau menyesuaikan dengan ketentuan kemudian baru diusulkan lagi untuk mendapatkan persetujuan SPM Angkutan Penyeberangan $^{[6]}$. 


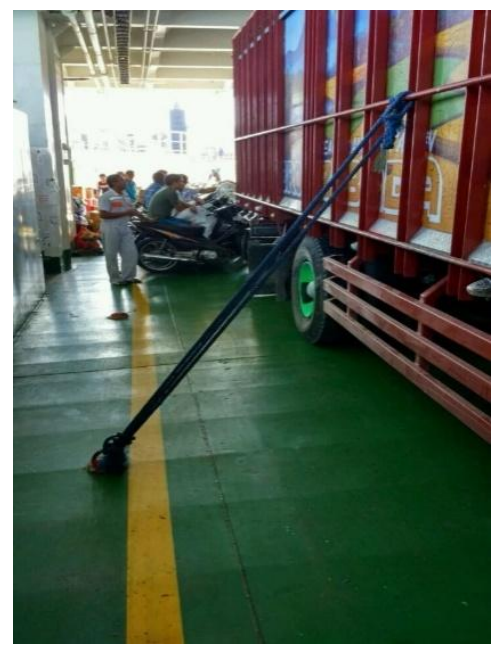

Gambar 6.Sistem Lasing pada KMP Legundi

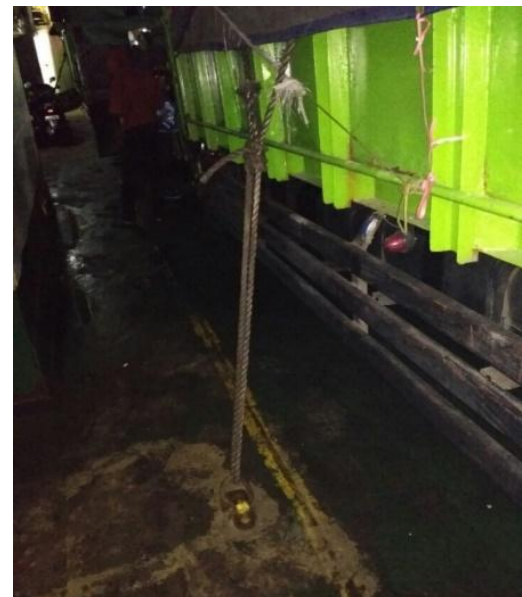

Gambar 7.Sistem Lasing pada KMP Legundi

\section{Operasional KMP. Legundi}

Waktu Pelayaran

Waktu pelayaran KMP LEGUNDI dengan kecepatan servis 15 knot adalah 20 jam dengan load mesin $75 \%$. Kecepatan kapal sesungguhnya dapat ditingkatkan dengan menaikkan load mesin hingga $85 \%$ namun akan berdampak pada pemborosan pemakaian bahan bakar. Sebagaimana diketahui bahwa pengisian bahan bakar hanya dilakukan di Surabaya karena fasilitas pengisian bahan bakar belum tersedia di Lembar.

\section{Fasilitas Akomodasi Penumpang}

Mengingat fasilitas akomodasi penumpang yang dimiliki oleh KMP. Legundi hanya untuk jarak pendek dengan waktu pelayaran yang singkat maka, KMP. Legundi tidak sesuai untuk dioperasikan di lintas penyeberangan yang jauh. Sesuai dengan Standar Pelayanan Minimal Angkutan Penumpang Penyeberanga, untuk pelayaran di atas 8 jam maka kapal harus dilengkapi dengan fasilitas tidur dan kamar mandi bagi penumpang.

Tempat Sandar dan Kondisi Bongkar Muat Kapal
KMP Legundi bersandar samping di pelabuhan laut Lembar dan Tanjung Perak yang tidak dilengkapi dengan fasilitas Movable Bridge. Oleh sebab itu, hanya 1 (satu) pintu rampa yang dapat digunakan untuk bongkar muat (loading and unloading) yakni pintu rampa serong buritan. Pintu rampa haluan dan buritan tidak dapat difungsikan pada pelabuhan ini.

Karena pelabuhan laut Lembar tidak dilengkapi dengan side elevated ramp way maka proses bongkar muat kendaraan hanya dapat dilakukan pada saat geladak kendaraan lebih tinggi dari atau sama dengan tinggi dengan permukaan dermaga. Hal ini terjadi pada kondisi air pasang maksimal.

Jika kondisi air surut, posisi geladak kendaraan lebih rendah dari permukaan dermaga sehingga sangat berbahaya untuk melakukan bongkar muat kendaraan karena bisa mengakibatkan konstruksi ramp door patah.

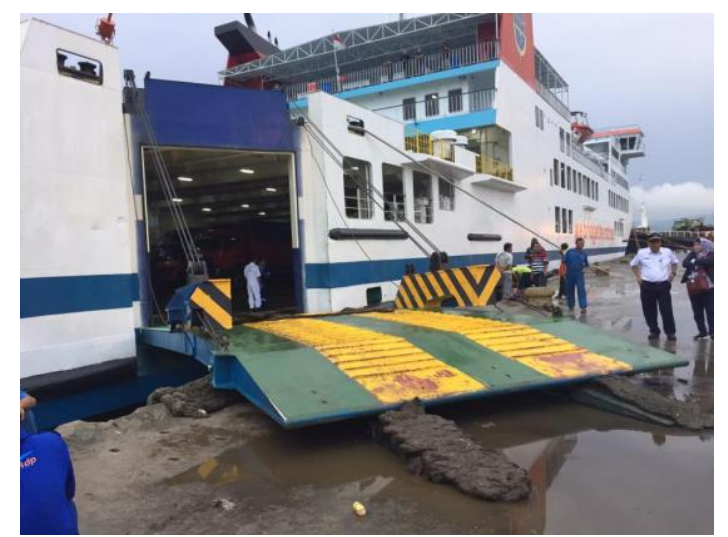

Gambar 8. Sistem Ramdoor KMP Legundi

\section{Kapasitas Angkut}

KMP. Legundi memiliki 3 (tiga) geladak kendaraan, namun demikian kendaraan yang terangkut didominasi truk-truk besar dan tronton dan hanya menempati geladak kendaraan utama. Hanya ada beberapa kendaraan pribadi / kecil yang ditempatkan di upper deck, sementara palka sedan tidak pernah dipergunakan untuk mengangkut kendaraan.

Walaupun payload area kendaraan masih sangat kecil, namun berdasarkan pengamatan pada tinggi sarat di posisi Plimsol Mark, terbukti bahwa tinggi sarat kapal sudah tercapai maksimal padahal tanki ballast dalam keadaan dikosongkan. Hal ini bisa terjadi karena bobot kendaraan beserta muatan yang diangkut sudah melewati batas maksimal yang disaratkan dalam desain kapal ini.

Dari Data Perhitungan Stabilitas Kapal (Stability Booklet) diketahui bahwa asumsi berat kendaraan dalam desain adalah sebagai berikut:

- Berat kendaraan sedan/mpv :4 ton

- Berat truk medium : 10 ton

- Berat tronton :30 ton

- berat trailer :40 ton 
Asumsi berat tersebut tentu saja digunakan juga dalam perhitungan konstruksi geladak kendaraan yang meliputi ketebalan pelat dan ukuran profile web.

Berdasarkan data pemuatan pelayaran KMP Legundi dari Surabaya ke Lembar, sempat terjadi over draft setinggi $20 \mathrm{~cm}$. Sesuai Data Hidrostatis Kapal diketahui bahwa nilai Ton Per Centimeter Immersion KMP. Legundi pada tinggi sarat 4,20 m adalah sebesar 17,202 ton. Hal ini berarti telah terjadi kelebihan muatan seberat 17,202 ton x 20 $\mathrm{cm}=344,04$ ton .

Sementara untuk pelayaran dari arah Lembar menuju Surabaya, tinggi sarat kapal rata-rata di bawah batas Plimsol Mark, padahal jumlah kendaraan yang diangkut relatif sama dengan dari Surabaya menuju Lembar. Hal ini berarti bahwa muatan yang diangkut dari Surabaya menuju Lembar jauh lebih besar dibandingkan dari Lembar menuju Surabaya.

\section{Jembatan Timbang dan Portal}

Dari pengamatan, pelabuhan laut di Surabaya dan Lembar tidak dilengkapi dengan jembatan timbang untuk mengendalikan bobot dan dimensi kendaraan yang naik ke kapal. Ini adalah salah satu penyebab kenapa berat muatan dari Surabaya menuju Lembar melebihi daya angkut kapal.

Ketidak-tersediaan jembatan timbang dan portal tersebut dan harga tiket yang relatif sangat murah dimanfaatkan oleh pengguna jasa untuk memaksimalkan pengankutan muatan melalui kapal tersebut.

\section{Perhitungan Beban}

Jika kapal mengalami kemiringan diasumsikan sebesar 6 derajat, maka benda yang berupa mobil ini akan bergeser akibat gaya gravitasi. Besarnya gaya yang dialami mobil ini tergantung pada sudut dan gaya gesek antara mobil dengan plat deck. Seandainya gaya gesek tersebut diabaikan maka besarnya gaya yang mempengaruhi mobil tersebut dapat diperkirakan menggunakan rumus : $\mathrm{N}=\mathrm{mg} \sin$

Diperkirakan benda (mobil) yang ada dalam kapal memiliki massa $40000 \mathrm{~kg}$

$\mathrm{N}=40000.10 \cdot \sin (6)$

$\mathrm{N}=41811.4 \mathrm{~N}$

Kemudian gaya gesek dari ban mobil sebesar :

Gesekan statik. fs $=\mu \mathrm{s} \times \mathrm{N}$

Gesekan dinamik. $\quad \mathrm{fk}=\mu \mathrm{k} \times \mathrm{N}$

Dari data konstanta gesek pada ban mobil adalah :

$$
\mu \mathrm{s}=0.325-0.375
$$$$
\mu \mathrm{k}=0.15-0.25
$$

Diasumsikan konstanta gesek yang digunakan adalah yang paling kecil atau minimum denganpertimbangan kondisi kritis pada gesekan roda.Maka pembebanan yang terjadi pada alat
adalahPembebanan bila mobil belum bergeser. (Huda; 2012)

$$
\begin{aligned}
& \mathrm{F}=\mathrm{N}-\mathrm{fs} \\
& \mathrm{F}=\mathrm{N}-(\mu \mathrm{s} \times \mathrm{N}) \\
& \mathrm{F}=41811.4-(0.325 \times 41811.4) \mathrm{N} \\
& \mathrm{F}=28222.7 \mathrm{~N}=28.2 \mathrm{kN}
\end{aligned}
$$

Pembebanan ketika mobil sedang bergeser $\mathrm{F}=\mathrm{N}-$ fk

$$
\begin{aligned}
& \mathrm{F}=\mathrm{N}-(\mu \mathrm{k} \times \mathrm{N}) \\
& \mathrm{F}=41811.4-(0.15 \times 41811.4) \mathrm{N} \\
& \mathrm{F}=35539.69 \mathrm{~N} \quad=35.5 \mathrm{kN}
\end{aligned}
$$

Dari perhitungan di atas didapatkan hasil alat yang digunakan harus bisa menahan beban sebesar $35.5 \mathrm{kN}$ ketikamobil sudah bergeser, karena sebelum mobil bergeser gaya masih dapat ditahanoleh gaya gesek statik pada ban mobil tersebut.

Tabel 1. Tabel Kapasistas Break Load untuk Chain Lasing (Panji ;2008)

\begin{tabular}{lll}
\hline Quality & Diameter,mm & $\begin{array}{l}\text { Breakload,kN } \\
\text { (ton) }\end{array}$ \\
\hline Grade 5 & 7 & $50(5)$ \\
Grade 5 & 9 & $75(7.5)$ \\
Grade 8 & 9 & $100(10)$ \\
Grade 8 & 11 & $150(15)$ \\
Grade 8 & 13 & $200(20)$ \\
\hline
\end{tabular}

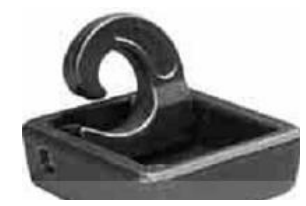

Gambar 8.Forged hook for welding dengan breaking strength: $60 \mathrm{kN}$ (6 ton) dan Weight 0.35 kg. (wikipedia;2017)

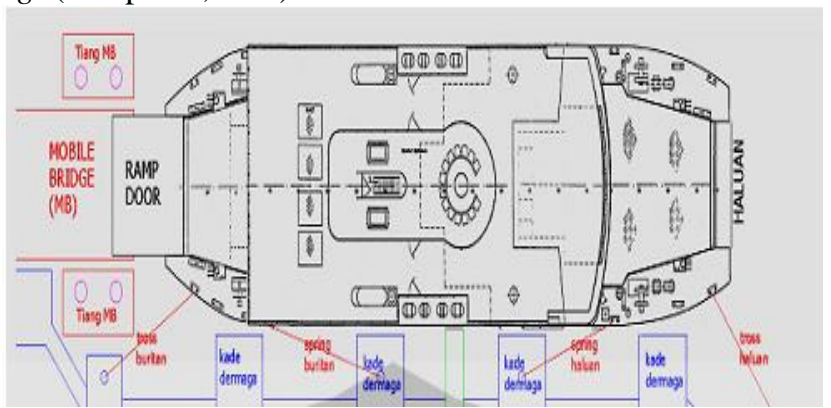

Gambar 9. Gambar Layout Car Deck (Panji 2008)

\section{KESIMPULAN}

- Belum maksimalnya kesadaran pihak penyedia jasa penyeberangan betapa pentingnya Lashing dan SPM untuk kenyamanan dan keamanan pengguna jasa.

- $\quad$ Lasing memerlukan jarak dan akan membuang ruang untuk muatan, tetapi jika lashing di terapkan akan dapat melokalisir / minimalisir gerak muatan di atas kapal agar tidak berbenturan dengan muatan lainnya. Jarak lashing yang sudah ditetapkan tersebut juga akan berdampak baik jika kapal dalam 
keadaan darurat (terbakar) karena akan memberi ruang untuk evakuasi dan ABK akan sigap untuk menangani keadaan darurat tersebut.

- Standar pelayanan minimal (SPM) di kapal sangat berpengaruh kepada penumpang karena selain penumpang aman penumpang pun juga merasa aman, karena sudah jelas ada petunjuk tentang evakuasi, petunjuk penggunaan pelampung, dsb. SPM ditetapkan agar mutu pelayanan penumpang dapat meningkat, sehingga pengguna jasa penyeberangan akan bertambah setiap harinya. Jika dari permasalahan di atas tidak di perbaiki oleh pihak penyedia jasa penyeberangan maka Pihak Otoritas Pelabuhan Penyeberangan akan memberi sanksi berupa pencabutan izin berlayar untuk kapal yang tidak sesuai dengan peraturan yang berlaku.

\section{SARAN}

Untuk mengatasi permasalahan yang teridentifikasi di lapangan sebagaimana kesimpulan di atas, maka disarankan kepada pihak penyedia jasa penyeberangan untuk:

- Menaati peraturan yang sudah didtetapkan ,dengan memberikan fasilitas pengunci seperti D-Ring, Chain Lasing sesuai dengan batas maximum yaitu ketika beban mobil bergeser bernilai $35,5 \mathrm{KN}$

- Usaha yang harus dilakukan untuk pencegahan pelanggaran tersebut yaitu dibutuhkannya marine surveyor yang bertugas untuk melakukan Lashing Survei setiap kapal beroperasi, dan mensurvei SPM kapal yang memenuhi standar. Usaha pencegahan tersebut sangat dibutuhkan untuk meminimalisir kecelakaan di transportasi penyeberangan.Terutama ketika cuaca buruk harus di laksanakan Lashing Survei lebih sering.

- Dari simulasi perhitungan tersebut didapatkan beban total ketika mobil bergeser sebesar 35,5 KN maka dapat menggunakan breaking strength: $60 \mathrm{kN}$ (6 ton) dan Weight $0.35 \mathrm{~kg}$ berdasarkan Tabel Kapasistas Break Load untuk Chain Lasing

\section{UCAPAN TERIMA KASIH}

Terima kasih disampaikan kepada Rektor Undip beserta bapak Dekan Sekolah Vokasi atas berbagai kesempatan untuk mengembangkan ide dan kegiatan penulis. Bapak Ir. H.Husain Saimima MT., OPP Lembar beserta jajarannya yang sangat membantu terlaksananya kegiatan kerjasama dan tulisan ini.

DAFTAR PUSTAKA

1. Kusuma, Panji, 2008. Analisis Sistem Lashing Pada Ferry Untuk Keselamatan Transportasi Laut. Jakarta : UI.

2. Lasse, D.A, 2012, Manajemen Peralatan aspek operasional dan Perawatan, Jakarta:Raja Grafindo Persada.

3. Lasse, D.A, 2012, Manajemen Kepelabuhan, Jakarta:Nika.

4. Ir. Marcus A. Talahatu MT., 1985, Teori Merancang Kapal. Jakarta:FT.UI.

5. Fransman, J. W., 1988, The influence of passenger ship superstructures on the response of the hull girder. UK: RINA Transaction.

6. R.P. Suyono, 2007, Shipping Pengangkutan Intermodal Eksport Import Melalui Laut, Musibah Kapal, Pencegahan dan Penanganannya, Keamanan Pelabuhan. Jakarta: PPPM.

7. Zanic, V., Jancijev, T., 1986, Structural design and analysis of night ferry 'Amorella' with 2200 passengers and 600 cars, Technical report for Brodosplit Shipyard.Croatia: University of Zagreb. 